\title{
O MERCADO DAS ESCOLAS DE ESTILISMO
}

\author{
Nicolas DiverT*
}

\begin{abstract}
RESUMO: Em cem anos, o número de franceses trabalhando na moda diminuiu em $93 \%$, o que acarretou uma modificação da estrutura da mão de obra empregada nesse setor. Perante a internacionalização crescente da economia, os países ocidentais tendem a dar as costas às atividades de produção para se concentrar nos ofícios com alto valor agregado. Entre eles, as atividades relacionadas à criação, realizadas pelos estilistas, estão em forte crescimento. Longe de estar à margem deste movimento, a escola acompanhou o deslocamento em direção a níveis mais elevados de escolaridade observados nos empregos propostos. A partir dos anos de 1970, cursos especializados na criação de moda começaram a ser criados. Inicialmente confiada à iniciativa pública, a oferta de formação foi crescendo, impulsionada por escolas privadas sem vínculos com o Estado. Um mercado da certificação escolar se configurou, no qual essas escolas tentam mostrar, em salões do estudante, uma relação estreita entre formação e emprego.
\end{abstract}

Palavras-chave: Estilismo. Escolas superiores privadas. Formação. Mercantilização.

\section{THE MARKET OF FASHION DESIGN SCHOOLS}

ABSTRACT: In a century, the number of French working in fashion has dropped $93 \%$, changing the structure of the employed labor. Faced with the increased internationalization of the economy, Western countries have let go off certain activities to concentrate on high value types of jobs. Among them, activities linked to creation, represented by fashion stylists, have developed. Far from being marginalized from that movement, schools have been keys to stimulate this trend on the employment market. Starting in the 1970s, specialized jobs in fashion creation have been offered by the public school system, first, but private schools have soon taken over and offered training and education. A market of scholar certifications is building up with these schools promoting, in fashion shows specifically designed for students, a tight relationship between education and employment.

Key words: Fashion design. Private education. Training. Commercialization.

* Sociólogo e professor na Universidade Paris Est Créteil (REV-Circeft). E-mail: nicolas.divert@u-pec.fr Tradução de Alain François, revista por Carolina Violante Peres. Tevisão técnica de Liliana Segnini. 


\section{Le MARCHE DES ECOLES DE STYLISME}

RÉSUMÉ: En un siècle, la population française travaillant dans la mode a chuté de 93\% entrainant une modification de la structure de la main-d'œuvre employée. Face à l'internationalisation croissante de l'économie, les pays occidentaux délaissent les activités de production pour se concentrer sur des métiers à forte valeur ajoutée. Parmi eux, les activités liées à la création, incarnées par les stylistes, connaissent une croissance importante. Loin d'être restée en marge de ce mouvement, l'école a été tenue d'accompagner le déplacement vers le haut des emplois proposés. A partir des années 1970, des cursus spécialisés dans la création de mode ont été instaurés. Relevant de l'initiative publique, l'offre de formation s'est ensuite accrue sous l'impulsion d'écoles privées sans lien avec l'Etat. Un marché de la certification scolaire se dessine où ces écoles mettent en scène, dans des salons destinés aux étudiants, une relation étroite entre formation et emploi.

Mots-clés: Stylisme. Écoles supérieures privées. Formation. Marchandisation.

\section{Introdução}

$\mathrm{N}$

a França, nesses cem últimos anos, a fisionomia do mundo da moda passou por uma mudança drástica. ${ }^{1}$ Paralelamente a uma produção de luxo erigida, com a alta costura, em referência nacional e internacional, uma produção industrial emergiu depois da Segunda Guerra Mundial e acabou se impondo definitivamente: o prêt-à-porter. Enquanto a alta costura é uma invenção francesa, o prêt-à-porter é a tradução literal de novos métodos de produção importados dos Estados Unidos pelos participantes das diferentes missões de produtividade. O objetivo, então, era o de reconstruir o tecido industrial francês e novos ofícios acabaram sendo introduzidos na França, entre eles o de estilista. Esses profissionais vão reivindicar a criação que se tornou uma questão central para todas as empresas do setor.

Essa evolução se inscreve num contexto em que os países com custos de mão de obra mais elevados estão se concentrando em funções com alto valor agregado. Entretanto, a valorização dessas atividades prestigiosas não pode ocultar que a moda está em crise, uma vez que a evolução dos empregos mostra uma queda de mais de $93 \%$ da população ativa que trabalha nesse setor em um século. ${ }^{2}$

Apesar desse declínio contínuo do emprego, uma oferta de formação hierarquizada foi elaborada e, em seguida, transformou-se drasticamente. A escola foi encarregada de acompanhar o deslocamento para o alto nas exigências de escolaridade dos empregos propostos, uma vez que cursos superiores estavam substituindo os diplomas de operários, cujos efetivos estavam diminuindo (Divert, 2010). Então, desqualificados no mercado de trabalho, esses diplomas ficaram pouco atraentes para os jovens e permanecem como currículos para alunos em dificuldade financeira. Essa 
situação destoa do desenvolvimento das escolas de estilismo, puxado por estabelecimentos privados, que formam cada vez mais estudantes no âmbito de um mercado da certificação.

Quando se refere a esse mercado, a sociologia francesa da educação designa principalmente o surgimento de um consumidor de escola (Ballion, 1982) que lança mão de estratégias escolares individualistas (contorna a setorização graças às opções, recorre a auxiliares educativos, como cursos supletivos). Reencontramos também esse consumidor nas análises recentes a respeito das consequências das políticas de regulação da educação pelas reformas da carte scolaire ${ }^{3}$ (Van Zanten \& Obin, 2008). Embora o termo "consumidor" permita distinguir o usuário interesseiro do simples usuário do sistema escolar, não se confunde com o de "cliente", pois a mediação do dinheiro intervém indiretamente. Segundo Cochoy, "a figura do cliente apresenta-se mesmo como um operador central de mercadorização da organização e de organização do mercado" (2002, p. 377). Entretanto, como se interessa principalmente pelo ensino primário e secundário, este amplamente regulado pelo Estado, a sociologia francesa da escola descreve um mercado sem considerar a dimensão mercantilização, isto é, sem transações financeiras. ${ }^{4}$ Ora, setores inteiros do ensino superior francês são ocupados por estabelecimentos privados cujo lugar é cada vez maior, uma vez que já acolhem 16\% da população estudantil (Fabre, 2008). Esses estabelecimentos operaram um deslocamento da educação para a formação (Tanguy, 2005), que faz da certificação um bem econômico em si, passível de troca durante transações financeiras num mercado.

Nesse mercado, a concorrência dos estabelecimentos favorece a difusão de discursos que apregoam a valorização de uma profissionalização cada vez mais avançada e, ao mesmo tempo, levam a desacreditar o ensino público, este apresentado como distante das necessidades do mercado de trabalho. Como o emprego se tornou uma preocupação comum aos pais, aos jovens e aos atores da formação, todo sistema de formação é intimado a ostentar seus vínculos com o mundo econômico. Estes são amplamente divulgados pelos diferentes "dispositivos de julgamento" (Karpik, 1996), cujo sucesso entre os "consumidores da escola" é proporcional às dificuldades de acesso ao emprego. Segundo Karpik, esses dispositivos são necessários para que os consumidores possam se orientar em mercados incertos, já que o preço não basta para tanto. Os estudos de estilismo pretendem formar para a criatividade, isto é, uma qualidade que não pode ser definida de modo preciso e, nessa economia da singularidade (Karpik, 1989; 2007) na qual se inscrevem, os salões e os guias destinados aos estudantes propõem-se a definir a "boa" escola e, com isso, participam da edificação de um mercado de formação em que as escolas particulares estão sobrerrepresentadas. 
Logo, este artigo estuda um segmento desconhecido do ensino superior francês no qual os estabelecimentos privados constituem a maioria da oferta de formação. Carreira pouco presente no ensino público, a criação de moda tem currículos desenvolvidos por empresas privadas que vêm investindo em massa nessa especialidade. E, como proclamam uma relação estreita entre formação e emprego, estão colocando o diploma no centro de trocas mercantis.

\section{A instauração de uma oferta de formação dedicada à criação de moda}

Independentemente dos pontos de referência temporais usados (um ano, uma década, um século), todos os dados estatísticos indicam o mesmo movimento de redução dos empregos. Esse setor, historicamente muito importante, está vendo o seu peso diminuir na indústria manufatureira francesa e, a cada ano, desde 2000, entre 5\% e 10\% dos empregos estão desaparecendo (Observatoire des Métiers de la Mode, des Textiles et du Cuir, 2008). Contudo, para divulgar a existência de um setor da moda sempre ativo, o termo criação é constantemente invocado.

Para acompanhar as mudanças de grande magnitude do mercado de trabalho, devidas à prioridade dada à criação e à internacionalização da economia, a variedade do ensino proposto cresceu e se fortaleceu; os primeiros currículos orientados para o estilismo foram instaurados nos anos de 1970.

Além do mais, as evoluções do mercado de trabalho têm elevado as exigências nos processos de recrutamentos. A educação e, a seguir, a formação tornaramse condições de acesso ao mercado de trabalho, pois esses dois mundos sociais foram postos em correspondência (Tanguy, 2002).

\section{O ensino superior privado ignorado pela sociologia da educação francesa}

Portanto, a partir do começo dos anos de 1970, instituições superiores de formação públicas e privadas têm progressivamente introduzido ensinos consagrados à criação no campo da moda e proposto estudos de estilismo. Embora muito mais estabelecimentos privados tenham participado dessa nova organização da oferta de formação, poucos estudos lhes foram consagrados na França. Quando analisa o ensino privado, a sociologia francesa interessa-se quase exclusivamente pelos estabelecimentos primários e secundários sob "contrato de associação com o Ministério da Educação (Éducation nationale)", o qual lhes proíbe benefícios em troca de um reconhecimento pela administração do Estado (Tanguy, 1972, p. 337). Em compensação, no ensino superior, um corte nítido separa os estabelecimentos públicos dos 
privados, os quais costumam ser empresas comerciais com fins lucrativos. Ora, o surgimento de uma relação comercial no ensino modifica a própria concepção da educação, pois difunde "normas de mercado" e "dispositivos de confiança" e abre esse segmento da atividade social aos especialistas em marketing (Cochoy, 1999).

Na obra que dedica ao Ensino privado na França, Monchambert (1993) evoca brevemente, na sua introdução, a existência de um ensino superior privado em pleno crescimento, mas não menciona o ensino privado não contratual. Do mesmo modo, as obras de síntese francesas que enfocam o sistema educativo não mencionam a distinção privado/público no ensino superior (Terrail, 1997; Van Zanten, 2000; Duru-Bellat \& Van Zanten, (1999) 2002), deixando de lado, assim, de forma nebulosa, os estabelecimentos privados, segundo a expressão de Menger (1997). A escassez de trabalhos sobre o ensino superior privado não permite apreender as consequências, para o conjunto do sistema de educação e formação, do modo de gestão desses estabelecimentos, que fazem da certificação um bem econômico cuja obtenção depende principalmente da posse de um capital financeiro. Distinguem-se, assim, do ensino público que valoriza o capital cultural como símbolo da meritocracia escolar.

\section{As escolas particulares de estilismo: empresas comerciais lucrativas}

Dada a importância crescente das atividades dos estilistas de moda, o Ministério da Educação nacional apoiou o projeto de criar um novo diploma para esses ofícios. Um Certificado de Técnico Superior (BTS - Brevet de Technicien Supérieur) de estilismo foi criado em 1972, cujo currículo concede um lugar importante às artes aplicadas. Durante quase dez anos, apenas um estabelecimento público localizado em Paris propôs esse diploma a um público muito restrito, uma vez que, em 1983, apenas 15 alunos estavam matriculados. Contudo, a atratividade desses estudos entre os jovens levou a uma defasagem crescente entre a demanda e a oferta de vagas. Então, as escolas particulares começaram a investir nessa especialidade pouco presente no ensino público. Um número crescente de currículos passou a ser proposto por uma grande variedade de escolas sem nenhum vínculo com o Estado, as quais marcariam de modo durável a oferta de formação de estilista, pois cresceram de 5 estabelecimentos, no início dos anos de 1970, a uns 50, em 2008, ao passo que apenas 8 estabelecimentos públicos preparam, hoje, para o BTS.

As escolas particulares sem contrato, isto é, sem qualquer vínculo com o Estado, investem em novas e atraentes especialidades de ensino superior para as quais há pouca oferta de formação pública e cujo acesso é limitado por uma seleção drástica. Os registros do tribunal de comércio mostram, por sinal, que as empresas comerciais são mais numerosas entre as escolas particulares francesas; os estabelecimentos com um estatuto de associação ou consulaires ${ }^{5}$ são amplamente minoritários (5 entre 
52). O estatuto jurídico adotado pela maioria das escolas de estilismo requer uma lucratividade financeira e as coloca à margem da organização habitual do sistema escolar. ${ }^{6}$ Mais numerosas, essas escolas são também mais ativas nesse mercado e recorrem a estratégias de desenvolvimento da esfera comercial.

Um terço das escolas particulares de estilismo francesas é composto por sociedades anônimas. Segundo o Code du Commerce, ${ }^{7}$ esse tipo de empresa exige o maior capital inicial, mas essas escolas são as que entregam mais diplomas, acolhem mais estudantes e estão engajadas numa vasta política de crescimento. Abriram escolas com o seu nome no interior, e, às vezes, no exterior, constituindo assim uma rede densa de filiais. Nesse mercado, como em muitos outros, a análise dos resultados financeiros permite afirmar que quanto mais as escolas propõem currículos variados, mais estudantes acolhem, o que aumenta o seu faturamento e os seus lucros. $\mathrm{O}$ caso da escola Esmod ilustra bem essa tendência.

Essa escola privada francesa, inicialmente instalada em Paris, inscreve-se na filiação dos cursos pagos organizados por seu fundador, Alexis Lavigne, em meados do século XIX, cujo objetivo era o de difundir os métodos de corte e costura que tinha elaborado. Até os anos de 1940, sua direção ficou entre as mãos dos descendentes do seu criador, primeiro a filha, e, em seguida, a neta. A partir de 1945, começou a se internacionalizar, mas continuou sendo uma instituição de formação para os ofícios técnicos do ramo do vestuário, principalmente modelismo e corte. No início dos anos de 1970, para acompanhar a chegada dos estilistas, o ensino orientou-se para a formação em criação de moda. Duas mulheres, oriundas do mundo da moda, foram nomeadas na direção da escola e associaram o estilismo ao modelismo na formação. A escola abriu filiais em outras cidades francesas e, a partir de 1984, no exterior, sendo que a primeira filial estrangeira foi criada no Japão, por um ex-aluno japonês. Outras também seriam abertas em países que vêm se afirmando como novas potências econômicas internacionais, entre eles o Brasil e a China, assim como em países sem qualquer tradição de aprendizagem da criação de moda (Alemanha, Austrália, Tunísia, Indonésia, Líbano). Hoje, o grupo Esmod tem umas 20 escolas em 11 países, e todas seguem o ensino elaborado em Paris. ${ }^{8}$

Essa rede de escolas atua no mercado internacional da formação, no qual favorece a circulação dos estudantes. Atualmente, apenas um terço do total dos alunos matriculados em suas escolas está escolarizado na França, país em que formam o maior número de estudantes por ano (aproximadamente 350 pessoas recebem, todo ano, um diploma de estilista da Esmod). Entre os estabelecimentos franceses, essa rede tinha, em 30 de junho de 2010, o maior faturamento (10.740.932 euros) e o lucro mais elevado (380.609 euros). Participa ativamente de todos os salões, é referida em todos os guias e as revistas a mencionam com frequência. Sua presença no campo da formação erige-a em ator incontornável nesse mercado e é 
uma referência regularmente invocada. Assim, no estudo comparativo das escolas de estilismo publicado por L'Étudiant, uma revista com site na internet que divulga informações sobre os estudos, Esmod é o estabelecimento mais mencionado pelos profissionais. ${ }^{9}$ Inversamente, as escolas menos midiatizadas e visíveis nos salões têm resultados financeiros menos importantes.

As escolas que apresentam os melhores resultados financeiros e entregam mais diplomas são também as que cobram as mensalidades mais elevadas (aproximadamente 9 mil euros por ano). ${ }^{10}$ Portanto, estes são elementos essenciais para a sua viabilidade. Entretanto, esses custos são constantemente ocultados nas apresentações para os futuros estudantes que focalizam a inserção profissional sempre bem-sucedida, ressaltada como marco de qualidade do ensino. Contudo, as taxas de matrícula e as mensalidades, isto é, o preço do acesso ao diploma, são usadas por essas escolas na construção de hierarquias. As mais caras ficam em Paris.

Nos seus trabalhos sobre a memória, Halbwachs enfatiza que o preço de uma mercadoria ou de um serviço não é o simples resultado da oferta e da demanda, mas o produto da representação que os indivíduos e as instituições elaboram do que deve ser considerado o preço justo ([1950], 1968). Os preços parecem funcionar como um indicador da qualidade para essas escolas e não é de se surpreender se as parisienses estão entre as mais caras. Apresentam-se como estando perto do mundo da moda e como tendo mais condições para uma inserção profissional nesse setor. Associam sempre o alto custo à qualidade elevada do ensino, o que justifica que as suas mensalidades aumentem regularmente.

\section{As modalidades de um crescimento muito rápido}

Na França, as escolas particulares respondem pela maioria das formações em estilismo e conhecem um sucesso crescente. Multiplicaram-se e metade delas foi criada nesses últimos 15 anos. Para explicar esse crescimento (em 1985, uns 15 estabelecimentos privados entregavam diplomas de estilista de moda, número que havia dobrado cinco anos depois) e o número de diplomas entregues, três tipos de razões podem ser invocados.

Consequência da divisão do trabalho e da globalização da economia. As organizações profissionais francesas e os poderes públicos concordam que é preciso se concentrar nas atividades com alto valor agregado como o marketing, a logística e as funções criativas. Desde o fim dos anos de 1980, todos os relatórios oficiais publicados sobre o setor da moda indicam que a produção parece definitivamente abandonada em proveito de atividades que exigem uma mão de obra altamente qualificada (OIT, 1987; Depin, 1995; Perotti-Reille, 2008). As políticas apoiam-se em 
slogans como "Paris, capital da moda" para divulgar uma imagem dinâmica do setor. Entretanto, não permitem compensar as destruições de empregos, nem explicar o crescimento da oferta de formação.

Do mesmo modo, a tese do recurso generalizado à formação, para ter acesso às funções ditas criativas, ajuda a dar conta da magnitude desse fenômeno, mas não me parece conseguir explicá-lo. Frequentar uma escola de moda parece cada vez mais central para a inserção profissional (Divert, 2009). Pode-se, então, ver nisso um sinal da individualização dos sucessos profissionais nos quais todos acreditam, e dos quais participam na esperança de "pintar e bordar". Embora essa crença pudesse explicar o crescimento da oferta, este é muito maior do que a demanda e o seu ritmo é muito acelerado. Em outras palavras, o mercado de trabalho não pode absorver todos os novos ingressantes.

Finalmente, ao se apresentar como trabalho de criação, o estilismo identificase com uma profissão artística, o que atrai muitas pessoas, pois, segundo Menger (2002, p. 7), mescla "uma atração por um espaço profissional de liberdade e de autodeterminação, e a desconfiança de frivolidade, de improdutividade para com o que se assemelha muito mais ao jogo do que ao trabalho". Mas, uma vez mais, a atratividade para esse ofício e esses estudos não explica por que a oferta de formação cresce tanto, principalmente no ensino privado sem vínculo com o Estado.

Esses três pontos informam que a demanda é prioritária. Ora, muitos pesquisadores mostraram a prevalência da oferta sobre a demanda em todos os níveis de ensino (Prost, 1992; Briand \& Chapoulie, 1993). Logo, trata-se de um fato sociológico geral e o crescimento da oferta privada somente parece poder ser explicado pelas diferenças que separam as escolas particulares dos estabelecimentos públicos.

Com exceção do respeito das regras de segurança, as quais se aplicam a todos os estabelecimentos que recebem público, o ensino privado sem contrato com o governo não está submetido às mesmas obrigações institucionais que o ensino público, no qual a abertura de um curso ou de uma filière devem ser justificados por uma necessidade claramente expressa e identificada. Como não são reconhecidas pelo Estado, as escolas particulares têm toda liberdade para escolher os métodos educativos, os saberes programados e os profissionais recrutados. Autonomia que se torna mais patente ainda quando os conhecimentos são pouco codificados e as expectativas, dificilmente submetidas a regras formais, como no ensino da criação. Assim, esses estudos são atípicos no ensino superior. Galodé e Michaut indicam três características dos estudos artísticos, que designam, em referência às outras disciplinas e filières, como três "faltas": "a falta de corpus de conhecimentos definidos, a falta de ordem estruturante da aprendizagem e a falta de referência 'acadêmica'" (2003, p. 321). Todas geram dificuldades para justificar a avaliação dos trabalhos dos estudantes (pois 
os critérios não seguem normas) e permitem o desenvolvimento de uma oferta de formação privada. Fora as instalações, os custos de pessoal e as despesas de funcionamento, os investimentos iniciais são relativamente limitados na medida em que esses estudos não exigem equipamentos custosos. Cada escola pode assim justificar sua abertura pela afirmação da sua especificidade num mundo do trabalho que valoriza a singularidade e, segundo a expressão de Heinich, da "obediência a essa norma paradoxal: a obrigação de não conformidade" (2006, p. 115). Para atendê-la, as escolas particulares investem na comunicação e divulgam um discurso que valoriza a inserção profissional para produzir uma demanda por parte dos jovens e de sua família.

No mercado da formação para o estilismo de moda, as escolas particulares desenvolvem uma oferta de vagas que têm de preencher suscitando uma demanda. Como em todos os outros mercados de bens e serviços comerciais, a oferta não pode ser infinita, mas o desafio, para essas escolas, consiste em criar a maior demanda possível.

\section{A educação no cerne de trocas comerciais}

A orientação vocacional e profissional é um momento de incerteza para muitos jovens e suas famílias, pois supõe escolhas, que costumam envolver coerções, em função das modalidades de recrutamento dos estabelecimentos, da sua localização, dos resultados escolares ou dos custos dos estudos. Entretanto, articula-se com o mercado de trabalho (Isambert-Jamati, 1972) e com a inserção profissional. Por isso algumas filières são apresentadas como saturadas ou obsoletas e outras como em plena expansão e gerando empregos. Quando se instaura essa relação entre a formação e o emprego, a escolha de uma filière expressa uma decisão fundamental num contexto de degradação da inserção profissional dos jovens e de crescimento do desemprego tal como os conhecemos desde meados dos anos de 1970.

Para que as famílias possam se guiar nos meandros do sistema escolar, empresas privadas têm investido no campo das informações escolares. Assim, tornamse atores da orientação, mas divulgam uma representação da oferta de formação na qual os estabelecimentos privados estão super-representados e são apresentados como os mais aptos a responder às expectativas do mercado, ao mesmo tempo em que desvalorizam o ensino público.

\section{Os salões do estudante: lugares de encenação das instituições de formação}

Para se nortearem no mercado das escolas de estilismo, os estudantes e os seus pais consultam guias e visitam salões especializados. Retomando os trabalhos 
de Karpik, podemos dizer que esses dispositivos dizem respeito aos "pareceres de experts" na medida em que os estudantes, como consumidores, confiam em "experts" que, supostamente, possuem um conhecimento perfeito do campo (Karpik, 2007). Ora, as sociedades que organizam esses salões e as editoras desses guias ganharam uma legitimidade que dá credibilidade às informações divulgadas, muito embora participem da organização desse mercado.

Duas firmas são particularmente ativas na difusão de informações escolares, L'Étudiant e Studyrama. A primeira existe desde 1972, ano em que publicou o primeiro número da revista Génération que, em 1977, mudou o seu nome para L'Étudiant. As informações são apresentadas de modo mais atraente do que nos suportes institucionais e as relações com o emprego são constantemente ostentadas. Em 1985, diante do próprio sucesso, a revista organizou o Salão do Estudante. Em poucos anos, ampliou a sua oferta de salões ${ }^{11}$ e parcerias com o Ministério da Educação (Éducation nationale) e a Onisep, ${ }^{12}$ que aumentaram a visibilidade, a notoriedade e a legitimidade do L'Étudiant, pois o seu nome estava associado a instituições públicas. Na esteira desse modelo, surgiu, no final dos anos de 1990, Studyrama, que também organiza salões e publica documentações destinadas aos jovens que estão completando o secundário.

Essas duas empresas têm em comum o fato de terem sido criadas por ex-alunos de comércio que consideram a orientação como um mercado econômico. Presentes em todo o sistema escolar graças aos seus salões e às suas diversas publicações, gratuitas ou pagas, essas empresas não são meros dispositivos de informação, pois moldam uma oferta comercial de formação na qual os estabelecimentos representados são praticamente todos privados e sem vínculo com o Estado. Para esses atores privados das informações escolares, as escolas particulares são clientes: anunciantes publicitários para os revistas ou expositores nos salões. A lógica comercial que rege essas relações exclui o ensino público cuja visibilidade é quase nula.

Ao contrário da maioria das feiras (Garcia-Parpet, 2005), os salões do estudante não são manifestações comerciais. Não envolvem transações comerciais ou assinaturas de contratos. Portanto, apresentam-se como lugares de informação nos quais o número de expositores, que garante a riqueza das informações providenciadas, é um desafio crucial para os organizadores. A sua capacidade para mobilizá-los em maior número é percebida como um sinal de exaustividade. Os expositores são inscritos no discurso publicitário na medida em que, quando do Salão do Estudante organizado em Paris em março de 2009, os convites distribuídos mencionavam a presença de 600 e o site na internet, de $800,{ }^{13}$ mas, a partir da lista oficial, contamos 320 expositores assim distribuídos: $84 \%$ de escolas, $8 \%$ de empresas comerciais sem vínculo com estudos (empresas de telefonia móvel, bancos, mutuais de seguros), $4 \%$ de associações de prevenção destinadas aos jovens e $4 \%$ de instituições públicas e organizações profissionais. 
Enquanto o ensino público envolve quase $85 \%$ do total dos estudantes, se considerarmos a totalidade das disciplinas oferecidas, aproximadamente $90 \%$ das instituições de formação presentes eram privadas. Nesses salões, todas essas escolas usam os mesmos termos de um discurso que visa a se filiar aos projetos escolares dos jovens pela afirmação de que a formação oferecida garante um emprego. Ora, esses estabelecimentos privados se multiplicam e diplomam cada vez mais jovens, independentemente das possibilidades de inserção.

Por sua vez, quando vão a esses salões, os jovens buscam obter a confirmação do seu projeto de orientação. Chegam com ideias precisas do que desejam encontrar e as escolas atendem plenamente as suas expectativas ao mobilizarem representações sociais comumente compartilhadas.

Todos os estandes das escolas de estilismo têm manequins usando trajes desenhados e realizados pelos estudantes, e expõem croquis de moda assim como diversos trabalhos que os representantes das escolas usam para ilustrar os ensinamentos ministrados. A maioria projeta em telões imagens dos desfiles de fim de ano que organizam. Essa encenação visa a mostrar uma formação concreta tomando sempre como referência o mundo do trabalho na moda, apresentado sob o seu aspecto mais estereotipado. Essa técnica de apresentação permite atender favoravelmente as expectativas dos visitantes, que acabam vendo o que estavam imaginando. As referências oriundas do mundo da moda são insistentemente evocadas para introduzir a ideia de que o acesso à escola é um acesso a esse mundo.

Como esses salões são lugares de interações, os representantes das escolas particulares interessam-se preferencialmente pelos jovens acompanhados por seus pais, porque podem dirigir-se a cada uma das partes. Com os futuros estudantes, evocam o ambiente sociável no qual os ensinamentos ocorrem, os conhecimentos artísticos transmitidos e o mundo da moda, mobilizando os nomes de grandes costureiros, de empresas da alta costura e de criadores de moda. Com os pais, valorizam o investimento escolar, sinal de um nível de exigência elevado. Assim, as escolas de estilismo apresentam-se como escolas de criação perante os jovens e como escolas profissionais diante dos pais.

Além do mais, privilegiam nas suas falas a inserção profissional. Esse argumento serve de contraponto às mensalidades muito elevadas e garante a adesão dos pais, dispostos a financiar estudos que, segundo lhes é mostrado, oferecem a certeza de encontrar um trabalho correspondendo à formação recebida. Portanto, a crença está no cerne das interações e a reprovação nos exames ou as dificuldades da inserção profissional nunca são cogitadas. Entretanto, se essas escolas podem garantir o acesso às formações e a obtenção de diplomas, consequências diretas da relação comercial que as vincula aos estudantes, não podem garantir a inserção, pois esta 
depende de mecanismos complexos e de um mercado de trabalho que não podem controlar.

A ostentação de vínculos com o mercado de trabalho substitui-se à apresentação do desenrolar da escolaridade e dos ensinamentos. O método usado para conceituar produtos inovadores caracterizando a criação nunca é explicitado, muito embora um dos objetivos primeiros do ensino seja o de disponibilizar um método de trabalho. Portanto, a avaliação da qualidade de uma escola não passa pelo preço, mas elabora-se exclusivamente a partir da ostentação da inserção no mercado de trabalho e de seus vínculos com o mundo da moda.

Paralelamente aos estandes das escolas, esses salões organizam palestras temáticas reunindo representantes de várias escolas em torno de um animador envolvido na organização do salão. Embora apresentadas como momentos de troca, apenas as escolas particulares participam e aproveitam para divulgar sempre o mesmo discurso centrado na inserção profissional. Regularmente, quando o animador pede para que apresentem seus currículos, ignoram a pergunta e continuam focalizando o mercado de trabalho.

Quando planejam fazer estudos de estilismo, todos os jovens se projetam nas empresas de luxo e, segundo os representantes dessas escolas, seus projetos são totalmente realistas, pois essas são as únicas experiências narradas durante as trocas com o público. Isso mostra o alcance simbólico do fato de mobilizar nomes de personalidades conhecidas por praticamente todo o mundo.

Assim, as escolas particulares participam de um mercado econômico e impõem, com os seus discursos, o critério da "boa" escola, isto é, aquela que garante um emprego. Contudo, as taxas de inserção que essas escolas apresentam costumam diferir dos poucos dados disponíveis. Apesar da ausência de estatísticas exaustivas e confiáveis, todos os dados conhecidos indicam que $50 \%$ dos estilistas estão desempregados (APCE, 1999) e que essa população é minimizada, uma vez que um estudo realizado pelo Departamento dos Estudos e da Prospectiva (Département des Etudes et de la Prospective - DEP), do Ministério da Cultura, mencionava uma população de aproximadamente 1.000 estilistas em atividade, 37\% dos quais se definiam como designers (Ministério da Cultura e da Comunicação, 1998). Ora, a cada ano, entre 500 e 600 estudantes chegam ao mercado de trabalho com um certificado ou diploma de estilista. Sabendo que esse mercado de trabalho está se internacionalizando, que escolas estrangeiras estão ganhando espaço e adquirem muita notoriedade no mundo inteiro e que os recrutamentos ignoram as fronteiras nacionais, muitos desses jovens não vão conseguir inserir-se no mundo da moda, ao contrário dos discursos tranquilizadores produzidos por essas escolas particulares. 


\section{A mercantilização do diploma escolar}

Ao instaurar uma relação comercial, essas escolas particulares transformam o estudante em cliente e contribuem para a mercantilização da formação. Tanguy mostrou que o uso do termo "formação", em vez de "educação", resulta da emergência na cena pública de um vínculo da educação à economia, que faz com que a formação se torne uma grandeza mensurável colocada no princípio da qualificação. Mesmo assim, se a formação dá acesso ao emprego, não garante a obtenção de uma qualificação como analisou essa autora (Tanguy, (1994) 1998; 2007). O êxito de todos os estudantes que cursam uma instituição privada resulta dessa relação, a qual é mascarada pela afirmação do valor "trabalho", como indica essa fala do diretor de uma escola privada de estilismo: "Todos passam de ano porque, aqui, estudam". Entretanto, os estudantes não se iludem e sabem que participam de um mercado e, portanto, que a obtenção do diploma constitui um dos termos de um contrato implícito: "Há um exame, mas, seja como for, sabemos muito bem que quem paga a escola somos nós. Enfim, sabe, temos uma espécie de... se preencher o cheque, tá tudo certo!" (Sandrine, 20 anos, escola privada de estilismo). Assim, os trabalhos de Duru-Bellat e Van Zanten a respeito do ensino primário e secundário tomam, no ensino superior privado, um alcance muito maior. Como essas autoras enfatizaram, para compreender o funcionamento do privado, é preciso sempre ter em mente que os alunos são clientes (Duru-Bellat \& Van Zanten, (1999) 2002). Esse movimento é ampliado pelo deslocamento progressivo do diploma, cuja entrega era monopólio do Estado, ao certificado pensado como um bem comum e que, assim, se torna um serviço avaliado em função de uma finalidade única: o emprego. Entretanto, apesar da ostentação de vínculos estreitos com o mundo da moda, este não intervém na definição dos conhecimentos transmitidos, de modo que os ensinamentos costumam ser construídos em função da necessidade percebida pelas empresas e não como consequência de necessidades claramente expressas. Além do mais, essa primazia dada à profissionalização e à empregabilidade dos formados faz das empresas lugares privilegiados de "formação", embora os estágios que oferecem raramente forneçam oportunidades de adquirir novos saberes e know-how.

A focalização das escolas particulares na inserção profissional, apresentada como sempre bem-sucedida, faz do estudante o único responsável pelo seu fracasso se não conseguir entrar no mercado de trabalho. Aliás, é tanto mais fácil para essas escolas fazer com que os estudantes adiram a esse ponto de vista que as funções para as quais estão sendo formados valorizam a singularidade e os sucessos individuais. A individualização da relação pedagógica naturaliza as diferenças de trajetórias profissionais, em particular em termos de desigualdades sexuais das carreiras. Numa sociedade que privilegia cada vez mais o indivíduo, os fracassos são racionalizados 
e interpretados como diferenças individuais e não como produto de desigualdades sociais. Assim, longe de constituir um elemento de enfraquecimento desses estabelecimentos privados, as diferenças de êxito são, pelo contrário, apresentadas como provas da individualização das trajetórias e autorizam cada um dos participantes a projetar o próprio sucesso. A lógica comercial e a lógica individualista superpõemse no sistema educativo e ocultam os mecanismos sociais de seleção da mão de obra nas funções vinculadas às atividades de criação.

O deslocamento semântico da educação à formação exprime mudanças profundas na afirmação das relações entre duas esferas de atividades, na realidade separadas, a educação e o trabalho. Léon, Naville ou Friedmann foram os primeiros a insistir na necessidade de um aprendizado completo que integre educação geral e aquisição de um ofício. Tratava-se de formar o cidadão e não apenas o trabalhador. Com a difusão da noção de formação, o interesse desloca-se dos conteúdos transmitidos à afirmação de objetivos vinculados à inserção profissional: "A educação foi pensada como um vetor de um futuro que ainda temos de fazer advir pelo registro político, ao passo que a formação, desde seus primórdios, está muito mais amarrada ao registro econômico" (Tanguy, 2005, p. 116). Além do mais, se considerarmos, com Terrail, que a tarefa historicamente atribuída ao sistema escolar reside na transmissão da cultura escrita, do campo do pensamento abstrato e da língua (2002), veremos a ruptura introduzida por essas escolas particulares que querem atender as expectativas das empresas e do mercado de trabalho.

\section{Para concluir}

A noção de mercado aplicada à formação permite apreender ao mesmo tempo as condutas estratégicas implementadas pelos "consumidores de escola" e a existência de uma transação comercial para ter acesso ao diploma. Esta surge como um bem de consumo cujas qualidades são alardeadas pela afirmação de seus vínculos com o mercado de trabalho, mantendo a adequação entre formação e emprego. Entretanto, essa crença nunca é definitivamente garantida uma vez que os estudantes a confrontam à realidade do funcionamento do mercado de trabalho.

A procura por empregabilidade dos alunos formados pelo sistema escolar transforma os estudantes em atores que devem ser capazes de efetuar as escolhas mais pertinentes a partir da sua orientação. Para tanto, precisam lançar mão de todas as ferramentas ao seu alcance e em particular dos salões e dos diferentes guias e revistas. Mostramos que esses dispositivos de ajuda à decisão moldam a oferta de formação para o estilismo ao enfocarem as escolas particulares não reconhecidas pelo Estado. Essas escolas instauram uma relação contratual com os estudantes e seus pais. Os estudantes sabem que a relação financeira que os vincula à escola 
garante que vão obter o seu diploma, este sendo sempre apresentado como acesso a prestigiosos postos e posições sociais. Progressivamente, até o final de seus estudos, vão discernir mais exatamente as suas possibilidades de integrar o mundo da moda, e a crença no discurso apresentado pelas escolas vai se esfarelando. Entretanto, as críticas formuladas pelos estudantes visam muito mais ao funcionamento do mercado de trabalho do que às escolas, de modo que dificilmente colocam em xeque a sua trajetória escolar e as suas escolhas.

Finalmente, o discurso tranquilizador que essas escolas particulares divulgam quando da orientação de seus futuros estudantes é contradito por sucessos profissionais aleatórios nos ramos artísticos, nos quais a valorização do risco se opõe à ostentação de garantia de encontrar um emprego. A inserção no mercado de trabalho dos diplomados por essas formações é incerta, mesmo se os rapazes têm mais trunfos para ocupar as posições mais prestigiosas, graças a mecanismos de afinidades eletivas (Divert, 2010). A moda tornou-se uma atividade globalizada, na qual assistimos a uma internacionalização das formações e dos recrutamentos para ter acesso às posições sociais mais desejáveis, dinâmica que reencontramos de modo recorrente entre as elites (Suleimain \& Mendras, 1995; Wagner, 1998). Observada no mercado de trabalho a partir da formação, a concorrência ressalta o mimetismo das práticas sociais nessas duas esferas sociais.

\section{Notas}

1. A moda é geralmente entendida como reunindo as atividades que têm em comum a "ornamentação" (parure) da pessoa (Ministério da Economia, das Finanças e da Indústria, 2005).

2. Em 1906, segundo o Instituto Nacional dos Estudos Demográficos (Ined), mais de 1.274.000 pessoas trabalhavam no ramo do vestuário (Fourastié, 1957) e, em 2006, apenas 87.250 (Forthac, 2008).

3. N. do T.: A "carte scolaire" (literalmente carta escolar) determina todo ano um recorte em setores dos departamentos e das cidades em função da previsão do número de alunos. Todo estabelecimento está inserido num setor geográfico, e os alunos devem ser escolarizados na escola ou no colégio do setor em que a sua família reside (Fonte: www.gouvernement.fr/gouvernement/la-carte-scolaire-aujourd-hui).

4. Felouzis e Perroton (2007, p. 694) escreveram: "A ideia de um mercado, fruto do encontro entre uma 'oferta' e uma 'demanda', não resiste muito tempo à análise na esfera educativa. E isso por uma razão essencial: a oferta escolar, na França, assim como na maioria dos países, é regida e regulada pela potência pública. Portanto não é o resultado de um puro mecanismo de mercado".

5. Um estabelecimento consulaire corresponde a um vínculo com a Câmara de Comércio e da Indústria. Parte das verbas para o seu funcionamento provém das mensalidades pagas pelos estudantes, e o resto, da taxa profissional, de contratos externos, das formações de profissionais, etc. 
6. Monchambert enfatiza que a "sociedade é um estatuto muito raramente escolhido pelos fundadores de estabelecimentos privados que hesitam em dar um intuito lucrativo ao seu estabelecimento para compartilhar os benefícios que poderão resultar dessa atividade" $^{\prime \prime}(1993$, p. 26).

7. O capital inicial de uma sociedade anônima deve estar em torno de 37 mil euros.

8. Nota da organizadora do Dossiê: no Brasil, a Esmod firmou convênio com o Senac, desde 1994.

9. Disponível em: <www.letudiant.fr/etudes/ecoles-specialisees/quelle-ecole-de-modechoisir-16019.html>. Acesso em: 13 jan. 2012.

10. Os preços praticados pelas escolas particulares variam entre 4.150 euros (escola Esmod em Balma) e 24 mil euros (escola Parsons em Paris), para estudos que duram de dois a quatro anos.

11. Entre os salões organizados por L'Etudiant, podem-se citar: salão especial grandes escolas, salão das formações internacionais, salão das formações artísticas, salão da formação continuada.

12. Ofício Nacional de Informação sobre Ensinamentos e Profissões.

13. Em março de 2009, o site na internet da revista L'Étudiant apresentava assim esse salão: "Espaços dedicados aos estudos e aos ofícios, polo internacional, palestras e especialistas do ensino e das formações, encontros-debates com profissionais... ao todo, oitocentos expositores se mobilizam para informá-los! Aproveitem!".

\section{Referências}

AGENCE POUR LA CRÉATION D'ENTREPRISE (APCE). Styliste. Les fiches sectorielles. Paris: APCE, 1999.

BALLION, R. Les consommateurs d'école: stratégies éducatives des familles. Paris: Stock, 1982.

BRIAND, J.-P.; CHAPOULIE, J.-M. L'institution scolaire et la scolarisation: une perspective d'ensemble. Revue Française de Sociologie, Paris, v. 34, n. 1, p. 3-42, 1993.

COCHOY, F. Une histoire du marketing. Paris: La Découverte, 1999.

COCHOY, F. Une petite histoire du client, ou la progressive normalisation du marché et de l'organisation. Sociologie du Travail, Paris, v. 44, p. 357-380, 2002.

DEPIN, F. L'industrie française du textile et de l'habillement: évolutions stratégiques. Paris: Fédération des Industries de la Maille, 1995.

DIVERT, N. Forme-t-on les stylistes?: comment le dictionnaire de la mode au XXe siècle donne à voir la formation des couturiers. In: APPAY, B.; JEFFERYS, S. (Coord.). Restructurations, précarisation, valeurs. Toulouse: Octarès, 2009. p. 351-363. 
DIVERT, N. De la couturière au grand couturier. 2010. 486p. Thèse (Doutorat) - Université Paris Ouest La Défense, Paris.

DURU-BELLAT, M.; VAN ZANTEN, A. Sociologie de l'école. Paris: Colin, (1999) 2002.

FABRE, É. Prévisions des effectifs dans l'enseignement supérieur pour les rentrées de 2008 à 2017. Note d'Information, Paris, n. 32, 2008.

FELOUZIS, G.; PERROTON, J. Les "marchés scolaires": une économie de la qualité. Revue Française de Sociologie, Paris, v. 48, n. 4, p. 693-722, 2007.

FRANCE. Ministère de la Culture et de la Communication. Les designers textile et surface. Développement Culturel, Paris, n. 125, 1998.

FRANCE. Ministère de l'Économie, des Finances et de l'Industrie. La mode en chiffres. Paris: Sessi, Ministère de l'Économie, des Finances et de l'Industrie, 2005.

FOURASTIÉ, J. Migrations professionnelles: données statistiques sur leur évolution dans divers pays de 1900 à 1955. Paris: INED, 1957.

FRIEDMANN, G. Le travail en miettes. Paris: Gallimard, (1958) 1964.

GALODÉ, G.; MICHAUT, C. Les études artistiques: hétérogénéité des écoles supérieures d'art, pratiques étudiantes et réussite scolaire. In: FELOUZIS, G. (Dir.). Les mutations actuelles de l'université. Paris: PUF, 2003. p. 317-340.

GARCIA-PARPET, M.-F. Le salon des vins de Loire: convivialité et vocation internationale. Ethnologie Française, Paris, v. 35, n. 1, p. 63-72, 2005.

HALBWACHS, M. La mémoire collective. Paris: PUF, (1950) 1968.

HEINICH, N. La sociologie à l'épreuve de l'art: $1^{\text {re }}$ partie. La Courneuve: Aux Lieux d'Être, 2006.

ISAMBERT-JAMATI, V. L'orientation scolaire. L'Orientation Scolaire et Professionnelle, Paris, n. 2, p. 29-141, 1972.

KARPIK, L. L'économie de la qualité. Revue Française de Sociologie, Paris, v. 30, n. 2, p. 187-210, 1989.

KARPIK, L. Dispositifs de confiance et engagements crédibles. Sociologie du Travail, Paris, v. 38, n. 4, p. 527-550, 1996.

KARPIK, L. L'économie des singularités. Paris: Gallimard, 2007.

LÉON, A. Histoire de l'éducation technique. Paris: PUF, (1961) 1968.

LÉON, A. Portrait de l'artiste en travailleur. Paris: Seuil, 2002. 
MENGER, P.-M. La profession de comédien. Paris: Ministère de la Culture et de la Communication, 1997.

MENGER, P.-M. Portrait de l'artiste en travailleur. Paris : Seuil, 2002.

MONCHAMBERT, S. L'enseignement privé en France. Paris: PUF, 1993.

NAVILLE, P. La formation professionnelle et l'école. Paris: PUF, 1948.

OBSERVATOIRE DES METIERS DE LA MODE, DES TEXTILES ET DU CUIR. Les chiffres de l'emploi. Clichy: Forthac, 2008.

ORGANISATION INTERNATIONALE DU TRAVAIL (OIT). Les incidences sur l'emploi et les revenus des changements structurels et technologiques dans l'industrie du vêtement. Genève: OIT, 1987.

PEROTTI-REILLE, C. Le textile-habillement. La volonté de remporter la nouvelle révolution industrielle. Paris: La Documentation Française, 2008.

PROST, A. Éducation, société et politiques. Une histoire de l'enseignement en France de 1945 à nos jours. Paris: Le Seuil, 1992.

SULEIMAN, E.; MENDRAS, H. (Dir.). Le recrutement des élites en Europe. Paris: La Découverte, 1995.

TANGUY, L. L'État et l'école. L'école privée en France. Revue Française de Sociologie, Paris, v. 13, n. 3, p. 325-375, 1972.

TANGUY, L. La formation, une activité sociale en voie de définition? In: DE COSTER, M.; PICHAULT, F. (Dir.). Traité de sociologie du travail. Paris, Bruxelles: De Boeck, (1994) 1998. p. 185-212.

TANGUY, L. La mise en équivalence de la formation avec l'emploi dans les IV et $V^{e}$ Plans (1962-1970). Revue Française de Sociologie, Paris, v. 43, n. 4, p. 685-709, 2002.

TANGUY, L. De l'éducation à la formation: quelles réformes? Éducation et Sociétés, Bruxelles, v. 16, n. 2, p. 99-122, 2005.

TANGUY, L. La fabrication d'un bien universel. In: BRUCY, G.; et al. Former pour réformer: retour sur la formation permanente (1945-2004). Paris: La Découverte, 2007. p. 31-68.

TERRAIL, J.-P. (Dir.). La scolarisation de la France: critique de l'état des lieux. Paris: La Dispute, 1997.

TERRAIL, J.-P. De l'inégalité scolaire. Paris: La Dispute, 2002. 
VAN ZANTEN, A. (Dir.). L'école, l'état de savoirs. Paris: La Découverte, 2000.

VAN ZANTEN, A.; OBIN, J.-P. La carte scolaire. Paris: PUF, 2008.

WAGNER, A.-C. Les nouvelles élites de la mondialisation: une immigration dorée en France. Paris: PUF, 1998.

Recebido em 18 de janeiro de 2012.

Aprovado em 24 de fevereiro de 2012 